\title{
Complex Service Process Optimization Based on Service Touchpoint Association and the Design Structure Matrix
}

\author{
Zhonghang Bai, ${ }^{1,2}$ Chang Liu, ${ }^{1,2}$ Huihui Sun, ${ }^{1,2}$ and Man Ding ${ }^{1}{ }^{1}$ \\ ${ }^{1}$ College of Architecture and Art Design, Hebei University of Technology, Tianjin 300130, China \\ ${ }^{2}$ National Technological Innovation Method and Tool Engineering, Hebei University of Technology, Tianjin 300130, China
}

Correspondence should be addressed to Man Ding; dingman@hebut.edu.cn

Received 18 June 2020; Revised 20 October 2020; Accepted 12 February 2021; Published 27 February 2021

Academic Editor: Tomas Veloz

Copyright $(2021$ Zhonghang Bai et al. This is an open access article distributed under the Creative Commons Attribution License, which permits unrestricted use, distribution, and reproduction in any medium, provided the original work is properly cited.

Service process optimization is conducive to the innovation of enterprise services, but the poor logic design of multiple touchpoints can easily lead to problems in the service process, such as scattered layouts and repeated paths. Aiming at the promotion of service innovation and user experience, this paper takes the optimization of a single service touchpoint as the prerequisite and proposes a service process optimization method based on service touchpoint association and the design structure matrix (DSM). The association of service touchpoints is categorized into two types, namely, noncoupled and coupled association. The DSM is used to describe the two types of association between service touchpoints, and the matrix operation is used for modular identification and layering of the two kinds of association. Finally, through the above steps, the problematic service process was replanned. By using the service process optimization of a new retail convenience store as an example, the service process is divided into 6 relatively independent modules, and the order of module execution is arranged. Moreover, the optimal service process of the convenience store system is determined, and the method is verified to be feasible. Through optimization both from single service touchpoint and service process modularization, the study provides a reference for process optimization of the complex service system.

\section{Introduction}

In today's business environment, service companies must constantly update their processes and products to remain competitive [1]. Academic research also reflects the growing focus on service innovation $[2,3]$. Service design plays a key role in service innovation and focuses on improving existing services or creating new services to introduce new service concepts into people's lives $[4,5]$. With the advent of the information age, the focus of service design has shifted from tangible products to intangible services [6]. As a system, the internal service touchpoints of service design are not static and isolated, but dynamic and interactive. The service process dynamically and flexibly connects various service touchpoints, and the process focuses more on user behavior and directly affects service experience; therefore, service process optimization is an entry point for service innovation [7] and is conducive to the improvement of user experience.
Service touchpoints are the main points of the service process [8]; thus, the optimization of the service process can be considered as the optimization process of a series of touchpoints with different associations.

In the experience economy, the "physical logic" that emphasizes the rational allocation of the physical properties of objects can no longer meet people's needs; however, the "behavioral logic" that emphasizes reasonable organizational behavior has increasingly attracted more attention [9]. Determining how to analyze problems with domain logic, understanding the nature of problems, and developing breakthrough solutions to improve and measure quality remain the key challenges in service design [10]. New online channels have led to a proliferation of touchpoints [11], and poor logic design between multiple touchpoints may cause problems such as scattered layouts, repeated paths [12], and the irregularity of sequences [13], which may cause poor service experiences. 
Therefore, the analysis of the association between different service touchpoints to rationally organize their logical order is crucial in service design. Most academic research on touchpoints focuses only on one type of touchpoint, namely, a specific combination of similar touchpoints [14]. The basic methods of service design such as customer journey map, service blueprint, and SERVQUAL all emphasize the expression of a single service touchpoint, but there are limitations in studying the association of touchpoints and service innovation. For example, a customer journey map is a graphical representation of touchpoints between customers and the organization. Although this visualization technology may help management understand the customer experience, it is basically useless in helping to promote innovation within the service system [15]. As the service design has become a hot spot, some scholars have tried to combine engineering or other fields to carry out service innovation. Lee et al. [16] proposed a novel knowledge-centric innovative service design (KISD) model by integrating memoryoriented-method CBR and nonmemory-oriented-method theory of TRIZ. Lee et al. [17] applies TRIZ to the intelligent parking service system. Wang et al. [18] integrated the existing fields of the TRIZ service design knowledge system and the emerging fields of the non-TRIZ service design knowledge system, and proposed a new system and a collaborative intelligence method-DSIT for creating and evaluating complex service systems using multi-criteria data analytics. Lee et al. [19] established a customer-centric approach to service conceptualization. This method combines abductive logic concepts-the EDGE approach-and the computer-aided system SCO explorer to solve the ambiguity, uncertainty, and unstructuredness of customer demand knowledge in the conceptualization of innovative data mining-based systems, and establishes a customer-centric service conceptualization method. It can be seen that these methods perform service innovation from different perspectives and have achieved good results, but they often neglect to consider the problem from the important perspective of touchpoints. In service innovation from the perspective of service touchpoints, the goal is not necessarily to create touchpoints, but to reorder or coordinate touchpoints. Touchpoints orchestration is generally considered the key to service success [20]. The purpose of this paper is to optimize the service process from the perspective of service touchpoint association. Because many service design methods are not suitable for studying service touchpoint association, methods outside the service design field are also considered for use to study the service touchpoint association. A design structure matrix (DSM) [21] can clearly describe the method of information transmission between various elements in a system, the information required by each element during the execution process, and the corresponding elements provided by the generated information [22]. Because the DSM has a unique role in information flow analysis, it is widely used in process optimization and other fields. Aiming at the problem of the reasonable organization of service touchpoint logic in service process optimization, this paper proposes a method for the optimization of the service process from the perspective of the service touchpoint association based on a DSM and a matrix operation. Service process optimization is inseparable from service modularization [23], and DSM is a common module division method. Applying DSM to the service design can describe the information dependence relationship between the touchpoints in the complex service system in the form of a matrix, and modularize and layer the touchpoints throughout the entire service process to finally achieve the optimization of the service process.

In order to fully improve user experience and make up for the shortcomings of single touchpoint optimization in service process optimization, this article optimizes the service process in two aspects: single service touchpoint and service touchpoint association. First, use the service touchpoint optimization method proposed by Bai et al. [24]. This method optimizes the problem of service touchpoint that affects the user experience in the service process from the micro perspective of the elements of touchpoint based on TRIZ and analogy design. Then, aiming at the problem of how to rationally organize the logic of service touchpoints in service process optimization, based on the DSM and the matrix operation, a method for optimizing service process from the macro perspective of service touchpoint association is proposed. And, the above methods were used to re-plan the service process of a convenience store in Tianjin.

The remainder of this paper is organized as follows. Section 2 presents a literature review of service touchpoint research and DSM methods. In Section 3, a method for the identification and layering of associated service touchpoints based on the DSM is proposed. Section 4 describes the overall flow of service process optimization based on service touchpoint association and DSM. Section 5 takes the optimization of the service process of an unmanned convenience store as an example, and uses this method. Section 6 describes the results of the case and verifies the feasibility and potential of the method. Finally, Section 7 presents the conclusion and the future outlook.

\section{Literature Review}

2.1. Service Touchpoints. Service touchpoints are derived from the service encounter theory [25] and are the "critical moment" of service encounters [8]. In 1985, Shostack [26] officially proposed the concept of service encounters when studying the problem of enterprise service quality management. He pointed out that service encounters between customers and service systems are a key factor that affects customer satisfaction. After decades of development, Larivière et al. [27] proposed the concept of "service encounters 2.0" based on the rapid development of technology, which include "any customer-company interaction that results from a service system consisting of interconnected technologies (owned by the company or customer), people (employees and customers), physical/digital environment, and company/customer processes." Although scholars have different understandings of the service encounter, they can be roughly divided into two categories: (1) the connotation of the narrow sense of binary contact service encounters [28] and (2) the connotation of broad, multi-interaction service 
encounters [26]. At present, scholars generally adopt the broad connotation of service encounters when conducting empirical research, i.e., all touchpoints of customers when they receive services are service contacts, and include technical touchpoints, physical entity touchpoints, interpersonal touchpoints, invisible touchpoints, etc. [29]. Service touchpoints run through every link of the entire service process and refer to the interaction points between users and service personnel, products, services, brands, etc., during service. The many and complicated touchpoints and the intangible experience involved present a major design challenge; however, each service touch point that occurs throughout the customer journey must be carefully designed and managed, and service innovation occurs at every touchpoint on this journey [8].

2.2. Service Process. Volpi and Paulino [30] emphasized that service is a process and proposed a service triangle consisting of three elements: service provider, customer, and media. The three interact with each other to complete service behaviors. By experiencing different touchpoints, customers can feel the value of the entire service process [31]. Therefore, some scholars have optimized the service process from the perspective of service touchpoints. Wang et al. [32] discerned customer touchpoints during user-product interaction by observing user behavior, proposed a customer touchpoint association model, and established a new service system. Kim et al. [33] explained the difference between automatic taxis and manned taxis via customer journey maps and touchpoints. In addition, via the design of touchpoints, he determined the issues that should be considered for the transformation of autonomous taxis. In the industry 4.0 environment, more emphasis is placed on effective communication between customers and manufacturers [34], which makes the service systems highly complex. The rapid growth of complex service systems has introduced new changes to the service design [35]. Customers begin to interact with service providers in a multichannel environment, and they use multiple channels in parallel and often switch between them, which increases the possibility of unsmooth service flow. A complex service system usually contains multiple service touchpoints, and the interactions between customers and service providers constitute service touchpoints. Therefore, it is necessary to research the association between service touchpoints to ensure that the service process is reasonable. Although some scholars have considered and explored the association between touchpoints in service design, the research method for this aspect is imperfect: Clatworthy [20] coordinated multiple touchpoints in the service process via integrated marketing, customer relationship management, and collaborative design research, which presented the first step in the establishment of a touchpoint knowledge system for service design. Roto et al. [36] proposed a multi-touchpoint experience design that combines service design (through multiple touchpoints), experience design (through the utilization of user needs), and omni-channel design (through the utilization of brand identity) to define company goals of customer satisfaction. The above research only stays at the stage of theoretical research, does not describe specific methods, and has not been applied in practice. In order to verify the necessity of the research on the association of service touchpoints, $\mathrm{Li}$ [37]considered the characteristics of children's medical institutions and enhanced the connection between touchpoints by considering the use of a unified theme design, making it easier for users to find corresponding clinics and play a guiding role. Cheng [38] proposed the principle of museum touchpoint construction: maintaining the association of the touchpoints and maintaining the consistency of the touchpoints, thereby bringing users a better user experience in the service process. These studies have confirmed the value of studying the association of touchpoints through some specific cases but have not formed a general method to optimize the service process from the perspective of service touchpoint association.

Service process modularization can not only improve service productivity but also improve customer satisfaction. Carlborg and Kindström [39] divide the service into 4 different types and propose the modularization strategy of service process, respectively. Luo et al. [40] realized the division of the service module by using the fuzzy tree graph on the basis of identifying and quantifying the correlation between the process activities of the service-oriented manufacturing system, so as to achieve the purpose of process improvement. Service process modularization is to analyze the whole service process and subdivide it into a series of activity elements, and then aggregate the activity elements with the same function into the same subprocess module according to dependencies between activities. Therefore, service touchpoints with high association can be divided into a module to guide service process optimization.

In view of the above research on service process optimization methods, this paper mainly studies the method of modularizing the service process from the perspective of service touchpoint association, after optimizing a single touchpoint.

2.3. DSM. A DSM maps the information dependency between tasks to a Boolean matrix, which is called Binary DSM. As shown in Figure 1, it is a design process consisting of $n$ subtasks. The relationship between the subtasks is mapped to a matrix, the rows and columns of which correspond to the $n$ subtasks. When the subtask ai requires the output information of the subtask $a j$, the matrix element $a i j=1$; otherwise, $a i j=0$. Nonzero values below the main diagonal of the DSM represent feed-forward information; nonzero values above the main diagonal represent feedback information, indicating that there is an iteration in the design process.

A DSM is derived from a directed graph, which can express the association between the corresponding activities of each node in the process through the arcs or edges between the nodes [41]. There is a one-to-one correspondence between the DSM and the directed graph, i.e., a unique directed graph can be drawn from a DSM; conversely, a unique DSM can be constructed based on a directed graph.

To establish a dynamic matrix model that reflects the essential connection of the design process, Daniel and Whitney [42] summarized the interaction between design 


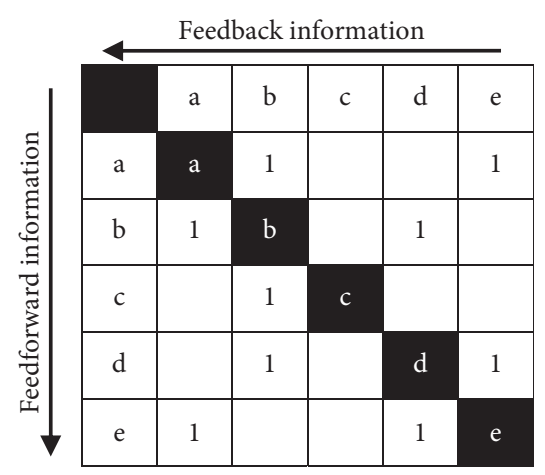

FIGURE 1: DSM.

activities (or tasks) into three forms, namely, serial dependence, parallel independence, and interactive coupling, as exhibited in Table 1.

(1) Serial dependence relationship: there is only one acting path between two design activities; the dynamic characteristics are expressed as a series of $\mathrm{A}$ and $\mathrm{B}$ activities

(2) Parallel independence relationship: there is no information interaction between two design activities, and there exists a completely independent mode of action; the dynamic characteristics are expressed as $A$ and $B$ activities that can be performed simultaneously

(3) Interactive coupling relationship: there is information interaction between the two design activities, and the information connection between $\mathrm{A}$ and $\mathrm{B}$ is two-way, i.e., activity A requires the information of activity $B$, and vice versa; the dynamic characteristics are expressed by $\mathrm{A}$ and $\mathrm{B}$, and only multiple iterations of the information between $B$ characteristics can complete the design task

A DSM is a modeling tool that identifies the relationship between tasks by displaying the information flow more efficiently [43]. Sari et al. [44] applied a DSM to the production process of dust filters and sorted their production process relevance to solve the problem of disorder in the production process. Marjanović et al. [45] proposed an enhanced DSM sorting algorithm based on gradient optimization. This method considers the driving factors of the product architecture and provides effective suggestions for the planning process. Zhang et al. [46] conducted a modular analysis of the medical process based on a DSM and genetic algorithm (GA), which reduced the complexity of the service process and increased the flexibility between the modules. Based on the analysis of the service processes, Yang and Shan [47] defined the association between service elements with a DSM and proposed a new business module identification method. It can be seen that DSM achieves process optimization by analyzing the relationship between elements and dividing modules. Most engineering design methods are proposed for smart products rather than smart services [48]. At present, most scholars' research on
DSM-based process optimization has also been aimed at product design processes, and the research on the application of service processes is scarce. In spite of there being a few applications in service design, they are only for specific areas, and there remains a lack of a set of methods that can be applied to most service process optimization scenarios. Although DSM was originally applied in the field of product design, the tasks in the product design process and the service touchpoints in the service process play similar roles, and both are the main elements of the process. Therefore, DSM can be used to analyze the relationship between different touchpoints, so that the service process can be modularized and layered. This paper introduces service touchpoints to the DSM, and aims to construct a process optimization method that can be applied to complex service systems with multiple service touchpoints, so as to solve the problems that affect user experience in the service process.

\section{DSM-Based Service Touchpoint Association Identification and Layering Method}

The purpose of the DSM-based service process optimization is to modularize and sort all service touchpoints with different associations to ensure both the rationality of the service process sequence and the location of touchpoints. By considering the service process as a design process, the service touchpoint is a subtask, and the interaction between the service touchpoints can be expressed by a DSM. First, a DSM of service touchpoints in the service system is constructed with the help of the graph theory.

A directed graph is an ordered pair $\langle V, E\rangle$, denoted as $G=\langle V, E\rangle$, where $V=\left\{v_{1}, v_{2}, \ldots, v_{n}\right\}$ is a finite set of nonempty nodes, $E$ is a set of finite edges, and each edge $e$ in $E$ corresponds to the node pair $\left(v_{i}, v_{j}\right)$.

Assuming that the nodes already have the order from $v_{1}$ to $v_{n}$, then the $n$-order square matrix $A=(a i j) n \times n$ is the adjacency matrix of $G(i, j=1,2, \ldots, n)$, where

$$
a i j= \begin{cases}1, & \text { if }\left(v_{i}, v_{j}\right) \in E \text { or }\left(v_{j}, v_{i}\right) \in E \\ 0, & \text { otherwise }\end{cases}
$$

If the touchpoint in the service process is regarded as the node $V$ in the directed graph $G$, and if the association between the touchpoints is regarded as the finite edge $E$, then the adjacency matrix of $G$ is actually the DSM of the action association between the service touchpoints. According to the functional association between the design activities proposed by Daniel et al. (see Table 1), service touchpoints are categorized into two types, namely, touchpoints with coupled or uncoupled association, respectively. Coupled-associated touchpoints include all touchpoints that have a two-way interaction with other touchpoints, while uncoupled-associated touchpoints include independent touchpoints that are parallel to all touchpoints and have the same unidirectional dependency association with some touchpoints. In the DSM, the two types of touchpoints are modularized and layered separately. 
TABLE 1: DSM and directed graphs describing the system characteristics. Associated description of three activities in the system.

\begin{tabular}{l|l|l|l|l|l|l|l|l|}
\hline Association & Serial dependency & Interactive coupling \\
\hline Association form & $\mathrm{A}$ & 0 & $\mathrm{~B}$ & $\mathrm{~B}$ \\
\hline DSM representation & $\mathrm{B}$ & 1 & & $\mathrm{~A}$ & $\mathrm{~B}$ \\
\hline
\end{tabular}

3.1. Identification and Layering of Uncoupled-Associated Touchpoints. In the initial DSM, touchpoints that only have the same one-way dependency with some touchpoints appear as zero row sums or zero column sums. (1) If the cells of a row element in the DSM are all empty, it means that the execution of the element does not require the input of information from other activities. This type of touchpoint is then placed at the front of the row (priority). (2) If the cells of a column element in the DSM are all empty, it means that the element has not output information to other activities after completion. The touchpoint is then arranged at the end of the column to be executed later. (3) The touchpoints that are independent of all touchpoints in parallel appear as zero row sum and zero column sum. Because this type of touchpoint will not be associated with other touchpoints, it can be executed in parallel with other activities without considering the order of such touchpoints. The uncoupled-associated touchpoints can be eliminated from the initial DSM to obtain the incidence matrix, $A$, of the initial DSM.

\subsection{Identification and Layering of Coupled-Associated} Touchpoints. In the service system, the coupled association between service touchpoints is the main reason for the complicated service process. In this case, a variety of matrix operations (division, splitting, joining, clustering) can be used to optimize the matrix based on the maximization of the identification of coupling activities. The relevant knowledge of the graph theory is used to modularize and layer the coupled-associated touchpoints in the DSM to reduce service process iteration and improve service efficiency.

According to the relevant knowledge of the graph theory, the problem of identifying coupled-associated touchpoints can be transformed into a problem of strongly connected components of the graph.

Definition 1. Let $\mathrm{u}$ and $\mathrm{v}$ be the two nodes in the directed graph $G=\langle V, E\rangle$. If there is a pathway from node $u$ to node $v$, it is said that node $u$ is reachable to node $v$. If any two nodes are mutually reachable, then $G$ is called a strongly connected graph [49].

Definition 2. Let $G=\langle V, E\rangle$ be a directed graph, where $V=\left\{v_{1}, v_{2}, \ldots, v_{n}\right\}$, and it is assumed that the nodes already have an order from $v_{1}$ to $v_{n}$. An $n$-order square matrix $P=$ (pij) $n \times n(i=j=1,2, \ldots, n)$ is defined, where

$p i j= \begin{cases}1, & \text { there is at least one non }- \text { zero length path from } v_{i} \text { to } v_{j} ; \\ 0, & \text { otherwise. }\end{cases}$

The matrix $P$ is called the reachability matrix of the graph, and can be obtained from the correlation matrix $A$ ( $A$ is a Boolean matrix, and its calculation rules follow those of Boolean algebra) via the following algorithm:

$$
\begin{aligned}
P= & (A+I) r=(A+I) r-1 \neq(A+I) r-2 \neq \cdots \neq A+I, \\
& r \leq n-1, I \text { is the identity matrix. }
\end{aligned}
$$

Definition 3. Let $P$ be the reachability matrix of $A$ and $P^{t}$ be the transposed matrix of $P$; then, $G$ 's strongly connected matrix $Q=P \cap P^{t}$.

$$
\begin{aligned}
Q & =P \cap P^{t}=\left[\begin{array}{cccc}
p_{11} & p_{12} & \cdots & p_{1 n} \\
p_{21} & p_{22} & \cdots & p_{2 n} \\
\vdots & \vdots & \ddots & \vdots \\
p_{n 1} & p_{n 2} & \ldots & p_{n n}
\end{array}\right] \cap\left[\begin{array}{cccc}
p_{11} & p_{21} & \ldots & p_{n 1} \\
p_{12} & p_{22} & \ldots & p_{n 2} \\
\vdots & \vdots & \ddots & \vdots \\
p_{1 n} & p_{2 n} & \ldots & p_{n n}
\end{array}\right] \\
& =\left[\begin{array}{cccc}
P_{11}^{2} & p_{12} p_{21} & \ldots & p_{1 n} p_{n 1} \\
p_{21} p_{12} & P_{22}^{2} & \ldots & p_{2 n} p_{n 2} \\
\vdots & \vdots & \ddots & \vdots \\
p_{n 1} p_{1 n} & p_{n 2} p_{2 n} & \ldots & P_{n n}^{2}
\end{array}\right] .
\end{aligned}
$$

Therefore, nodes $v_{i}$ and $v_{j}$ are mutually reachable if and only if $p i j \cdot p j i=1$. Thus, if the nonzero element of the $i$-th row of the matrix $Q$ is in the $j 1, j 2, \ldots, j k$-th columns, then the nodes $v i, v j 1, v j 2, \ldots, v j k$ are in the same strongly connected component. The subgraph derived from $\{v i, v j 1, v j 2, \ldots, v j k\}$ is then a strongly connected component of $G$ [49]. It can be determined from the graph theory that service touchpoints in the same strongly connected component have the largest coupled association, so they can be clustered into one module. 
Definition 4. The service touchpoints in the same strongly connected component are at the same level. Therefore, one of the service touchpoints can be selected to represent a strongly connected component. The reduced matrix $P^{\prime}$ can be obtained by reducing the reachability matrix $P$.

Definition 5. For each node $v_{i}$, the set of its reachable nodes is defined as $v_{i}$ 's reachable set $R(\mathrm{Vi})$. $\mathrm{R}$ is composed of the nodes corresponding to the columns where all elements in the row in the DSM in which Vi is are "1." Similarly, the set of nodes that reach $v_{i}$ is defined as the predecessor set $A(V i)$, which is composed of nodes corresponding to rows where all elements in the column in the DSM in which $V i$ is are " 1 " [50]. The reachable set $R(V i)$ and the predecessor set $A(V i)$ of the matrix $A$ are determined according to the reachability matrix $P^{\prime}$. The element $\sum V_{n}$ of $R(V i) \cap A(V i)=R(V i)$ is determined. The strongly connected component represented by the touchpoint $V_{n}$ is then at the highest level in the strongly connected subset L1. By removing the highest level, the L2 and L3 layers can be obtained in turn.

\section{Service Process Optimization Flow Based on Service Touchpoint Association and the DSM}

Service process optimization based on service touchpoint association and DSM is a process of using DSM to describe service touchpoint association on the premise of single service touchpoint optimization, and then identifying and ordering the touchpoint with matrix operation. The optimization flow is presented in Figure 2, and it includes four components: (1) optimization of single service touchpoint; (2) construction of a service touchpoint DSM; (3) identification of coupled and uncoupled service touchpoints; and (4) level analysis of service touchpoints.

4.1. Optimization of Single Service Touchpoint. Single service touchpoint optimization adopts the method proposed by BAI Zhong-hang. According to the model of analogy problem-solving, the interaction relationship between the components of the service touchpoint that affect the user experience is analogized with the substance-field model, so as to construct the service touchpoint model. Then, with the guidance of standard solutions, the problems existing between service touchpoint components are solved.

4.1.1. Identification of Problem Service Touchpoints. Obtain all service touchpoints of the service system according to field observation and other research methods. Combining the results of the survey, set up offline survey questionnaires to quantify customer satisfaction with the convenience store shopping experience, obtain problem service touchpoints, and tap new user needs.

\subsubsection{Problem Service Touchpoint Model Construction.} First, analyze the problem touchpoints to be optimized to find out the customer components, service provider components, and media components of the touchpoint, and then analyze the relationship between each component (lack/ harmful/insufficient) to determine the role of the service touchpoint components' types of relationships. Finally, the problem touchpoint model is constructed.

4.1.3. Optimization of Problem Service Touchpoints. Combining the analysis of the function relationship of the service touchpoint model, query and apply the type 1, 2, 3, and 5 standard solutions to solve the problem, specifically:

Step 1. Combining the function relationship of the service touch point model, query and apply the type 1 or type 2 standard solution to solve the problem. Among them, when the model interaction type is lacking, the type 1.1 standard solution is queried and applied; when the model interaction type is harmful, the type 1.2 standard solution is queried and applied; when the model interaction type is insufficient, the type 1.1 or type 2 standard solution is queried and applied. In the process of standard solution query, system resource analysis and design constraint analysis can be combined to select sublevel standard solutions.

Step 2. Query and apply the type 3 standard solution to further improve the above optimized system.

Step 3. Evaluate the optimization plan for service touchpoints. Design the survey questionnaire again to investigate the user's satisfaction with the optimized service touchpoint, and compare it with the user satisfaction before the optimization. Determine whether the service touchpoint model optimization plan is sufficient. If not, return to step 1; if the optimization plan is sufficient but you want a better plan, query and apply the type 5 standard solution.

Step 4. Query and apply type 5 standard solutions to further optimize service touchpoints.

4.2. Construction of Service Touchpoint DSM. A DSM can express the service touchpoints and their interaction in the form of a matrix. According to the directed graph of service touchpoints, a matrix of different associations of service touchpoints in the service process can be constructed. This includes the following two steps:

(1) Draw a directed graph of the service system. First, determine the set of service touchpoints after the optimized service system for a single touchpoint and then analyze the interactions between them. Finally, determine the directed edge according to the action association between the service touchpoints and Definition 1, thereby creating a directed graph.

(2) Build a service touchpoint DSM. Determine the initial DSM corresponding to the directed graph in step 1 and Definition 2.

4.3. Identification of Coupled and Uncoupled Service Touchpoints. Service touchpoint identification is the division of the touchpoints into two categories and their separate 


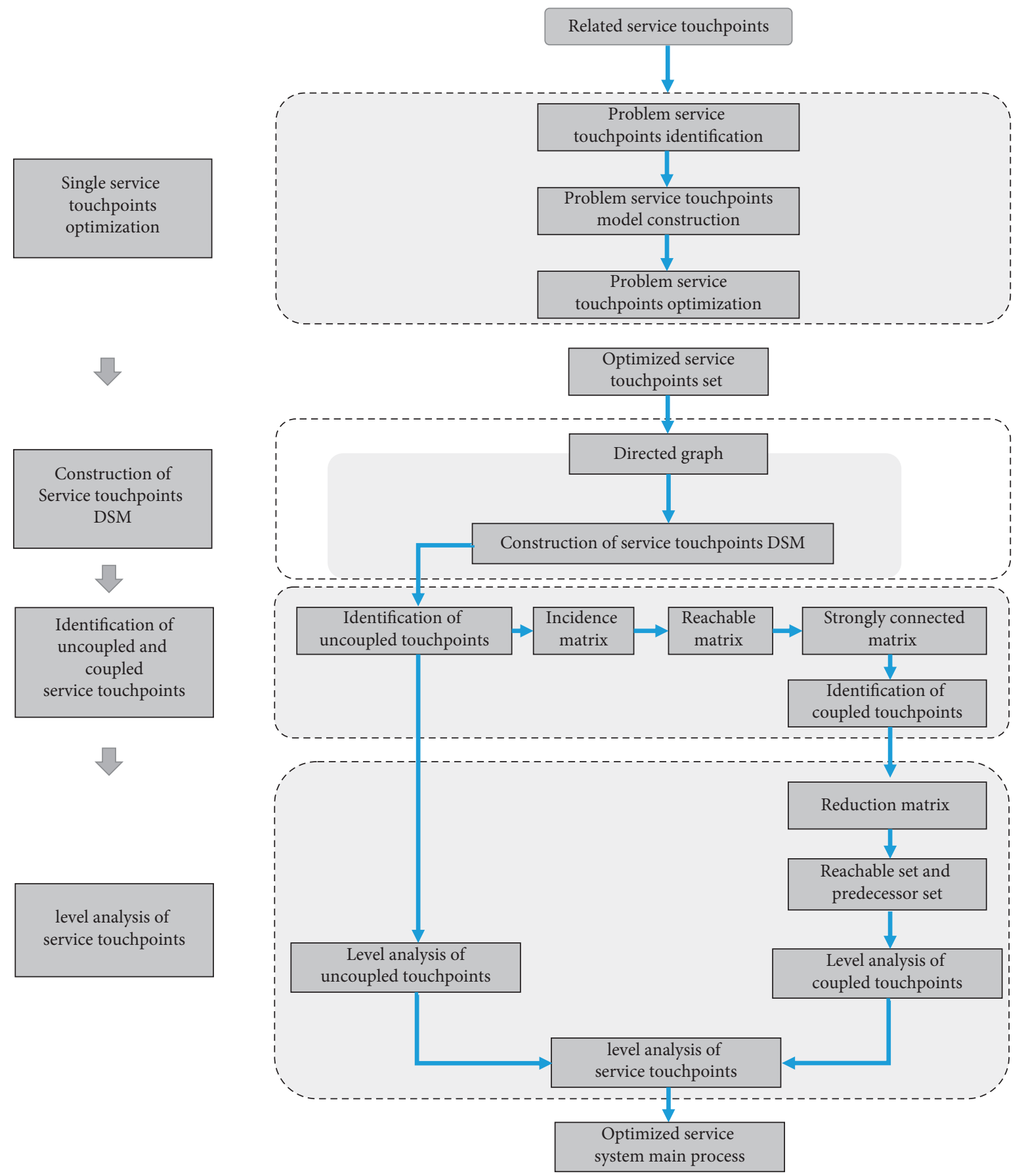

FIGURE 2: Service process optimization flow based on service touchpoints' association and DSM.

identification. This process is divided into two steps, namely, the identification of uncoupled touchpoints and the identification of coupled touchpoints.

(1) Identification of uncoupled touchpoints. According to the initial DSM, the elements corresponding to the zero row and the zero column can be obtained; the touchpoints corresponding to these elements are uncoupled touchpoints.

(2) Identification of coupled touchpoints. The purpose of the identification of coupled touchpoints is to modularize touchpoints with high degrees of association via the matrix operation, which is divided into the following steps. (a) Eliminate uncoupled touchpoints to obtain the incidence matrix A. (b) Derive the reachable matrix $\mathrm{P}$ according to Definition 2. (c) According to Definition 3, derive the strongly connected matrix $Q$ and the strongly connected components. (d) The service touchpoints in the strongly connected component are strongly related, so they are coupled touchpoints. The coupled touchpoints constitute a coupling module. 
4.4. Level Analysis of Service Touchpoints. The establishment of a service system reachability matrix can clarify the levels of activities and structural details. The purpose of the DSM level division is to divide the coupling modules into different levels according to the priority order. The steps to find the hierarchical relationship of service touchpoints based on the reachability matrix are as follows:

(1) Level analysis of coupled-associated touchpoints. According to the content of uncoupled-associated touchpoints identified in Sections 4.3 (1) and 3.1, the uncoupled-associated touchpoints are given either priority or endmost execution.

(2) Level analysis of uncoupled-associated touchpoints. (a) According to Definition 4, the reduction matrix $P^{\prime}$ of the reachable matrix is obtained by reduction transformation. (b) The highest layer L1 of the coupling module is determined based on the reduction matrix $P^{\prime}$ and Definition 5. (c) The highestlevel element of the coupling module is removed, and the previous step (b) is then performed. The coupling module levels L2, L3, etc., can be determined in turn.

(3) According to the execution order of uncoupled and coupled touchpoints, the overall relationship of each touchpoint module in the service process can be obtained.

\section{Convenience Store Service Process Optimization Based on Service Touchpoint Association and DSM}

In the era of "new retail," convenience stores, as one of the foremost scenarios of community consumption, have become an important entry point of user traffic. For consumers, the convenience store mainly carries emergency needs and smallscale fragmented shopping needs, and therefore provides great convenience. The development of domestic convenience stores is mainly concentrated in Beijing, Shanghai, and domestic capital cities. The new retail model of convenience stores has broad prospects in the country. However, due to their late start, various institutional facilities remain imperfect and are prone to problems such as cumbersome service processes and poor user experience.

Based on the principle of "user-centered" in service design, this paper takes the convenience store on Wu'ai Road in Tianjin as an example, to optimize the offline experience of customers in the convenience store. Specifically, it is the process of optimizing the convenience store service process from the customer's point of view, taking the optimization of a single service touchpoint as the premise, using DSM to integrate and sort all touchpoints in the customer's shopping behavior. Experience the entire service process through the method of service travel to discover the bad experiences in the process, as shown in Figure 3. By experiencing the service process, the service touchpoints of the convenience store can be obtained accordingly, as shown in Table 2.

Based on the previous survey results, a customer journey map was drawn, as shown in Figure 4. It can be clearly seen that there are repetitions and twists in the customer shopping process.

\subsection{Optimization of Single Service Touchpoint}

5.1.1. Identification of Problem Service Touchpoints. A questionnaire was designed based on the service touchpoints obtained from the above survey. A Likert five-level scale was used to score the satisfaction of convenience store service touchpoints and randomly sent to the surrounding users who had experienced the convenience store. The results of the questionnaire show that customers have the lowest satisfaction in the analysis stage of the commodity competition. Exploring the specific reasons for the low satisfaction at this stage through user interviews, it is found that customers are mainly dissatisfied with the price discounts and promotional activities of the commodity, which leads to the lack of satisfactory commodity in the analysis of commodity competition. After consulting the data, it is found that the high cost of convenience stores has forced them to maintain normal operations by increasing the gross profit margin of the commodity, and the excessively high gross profit margin will affect the price of the commodity and thus affect customer satisfaction. The survey results of the "2019 China Convenience Store Prosperity Index Report" show that turnover, total monthly cost (distribution of losses, water and electricity property costs, tax company management and other miscellaneous expenses, labor costs, etc.), and monthly rent affect the cost of convenience stores. Among them, the development pressure of convenience stores mainly comes from rent cost and labor cost. This article focuses on solving the problem of labor service cost that causes low satisfaction with the touchpoint of commodity competition analysis.

\subsubsection{Construction of Service Touchpoint Model of Com-} modity Competition Analysis. In the convenience store service system, in order to improve the user shopping experience and increase satisfaction, the convenience store staff provides customers with many manual services such as loading, replenishment, consulting, and cashier. However, the increase in labor costs has increased the selling price of the commodity and affected the satisfaction of users in the analysis of competing commodity. Analyze the touchpoint of this process: the process provides the corresponding service demand information, achieves the established design purpose, and belongs to the integrity of the model, but the interaction between the components produces harmful effects (increased cost, affecting user experience). Establish the corresponding touchpoint model, as shown in Figure 5. The customer component $\mathrm{C}$ is the consumer, the service provider component $\mathrm{P}$ is the convenience store (employee), and the media component $\mathrm{M}$ is the information.

\subsubsection{Optimization of Problem Service Touchpoints}

Step 1. Query the standard solution based on the analysis of the service touchpoint model in Figure 5. 

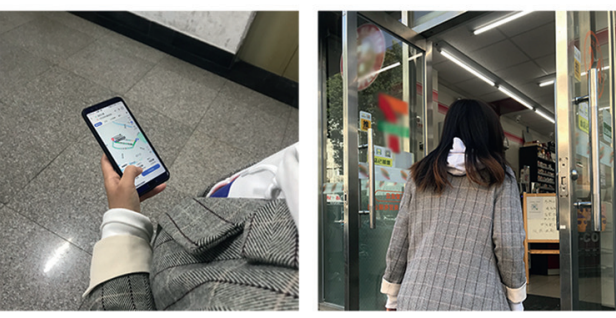

Map navigation to shop

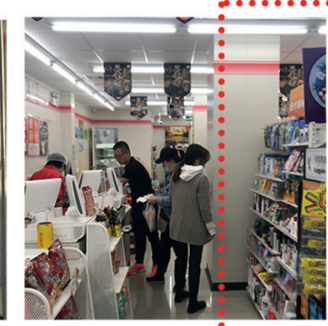

$\Rightarrow$ Browse store:layout

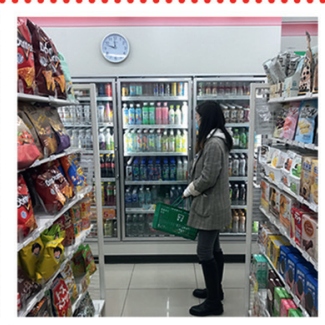
Find the commodity:you need

Feeling: It's easy to get lost because you have to go back and forth

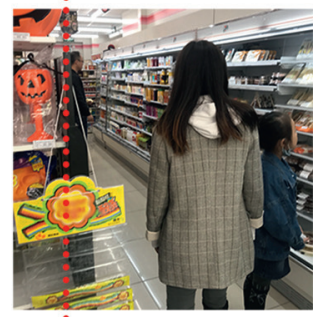
between the shelves to pick the goods

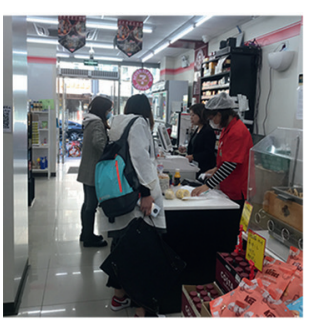

Cashier payment

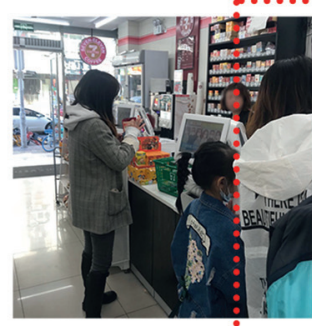

Check shopping:list

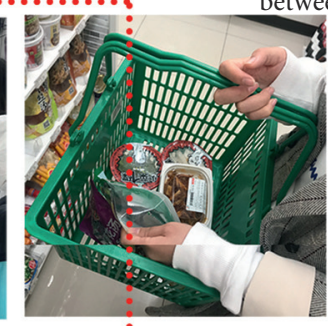

Identify: the

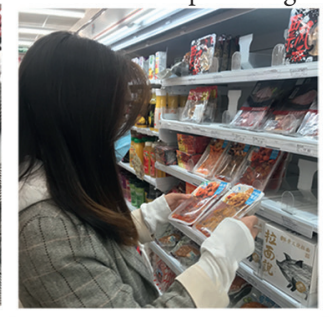

Commodity analysis

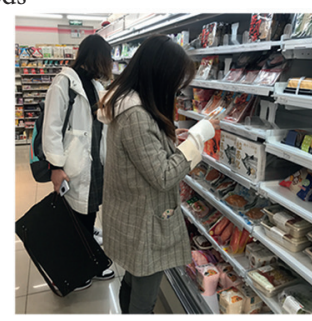

View commodity information
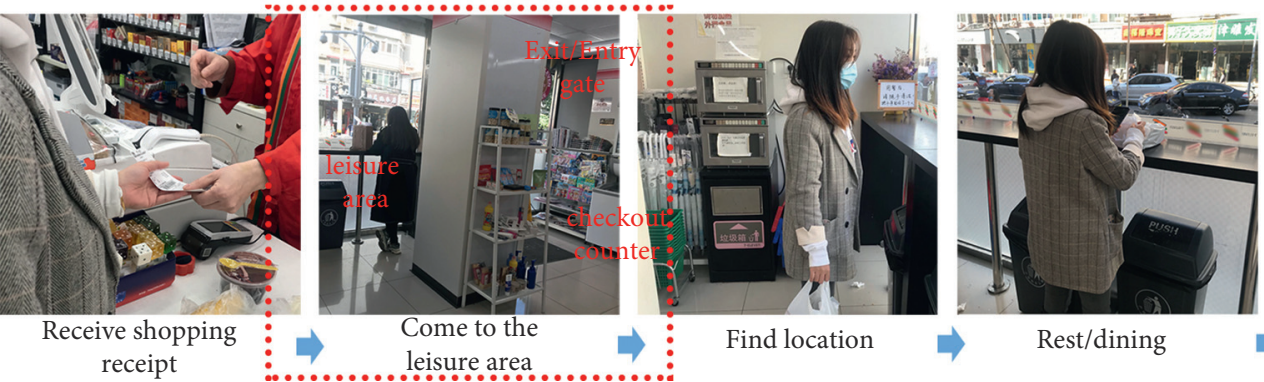

Rest/dining

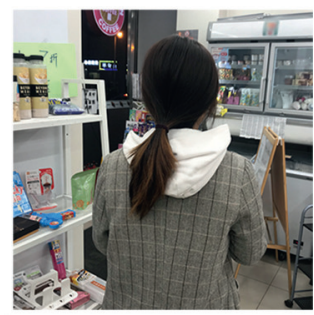

Leave the store

Feeling: you need to turn back when you go to the leisure area after you check out

FIgURE 3: Convenience store service process experience.

TABLE 2: Summary of service touchpoints of convenience store system.

\begin{tabular}{|c|c|}
\hline Shopping phase & Service touchpoints \\
\hline Before shopping & $\begin{array}{l}\text { (a) Generate shopping demand } \\
\text { (b) Map navigation to the store }\end{array}$ \\
\hline Shopping & $\begin{array}{l}\text { (c) Browse store layout } \\
\text { (d) Find the commodity you need } \\
\text { (e) View commodity information } \\
\text { (f) Commodity analysis } \\
\text { (g) Identify the commodity (end of shopping) } \\
\text { (h) Check shopping list } \\
\text { (i) Cashier payment } \\
\text { (j) Receive shopping receipt }\end{array}$ \\
\hline After shopping & $\begin{array}{l}\text { (k) Come to the leisure area } \\
\text { (l) Find a seat } \\
\text { (m) Rest/dining } \\
\text { (n) Evaluation feedback } \\
\text { (o) Leave the store } \\
\text { (p) After-sales service }\end{array}$ \\
\hline
\end{tabular}

First, according to the standard solution classification in TRIZ, the type 1.2 (No. 9-No. 13) standard solution is initially selected for solving the problem.
Secondly, analyze the system resources and design constraints, and select the appropriate sublevel standard solution. Combined with the analysis of the internal and external resources of the touchpoint system and related design constraints, as shown in Table 3, the selection of standard solution No. 9 has both useful and harmful effects in a system. S1 and S2 do not need to be in direct contact. S3 is introduced to eliminate harmful effects to guide the specific scheme generation.

Finally, use system resources to establish specific solutions. As traditional retail companies face the dilemma of high cost and low growth, using new technologies such as the Internet to achieve "open source and reduce expenditure" and reduce corporate costs is an effective way to enhance corporate competitiveness. In response to this problem, part of the work of the convenience store is undertaken through the application of new technologies, which can reduce the number of employees employed by the convenience store and reduce or even eliminate the harmful effects caused by labor costs. Through the application of new technologies such as artificial intelligence, EPC system network, and big data, a reasonable division 


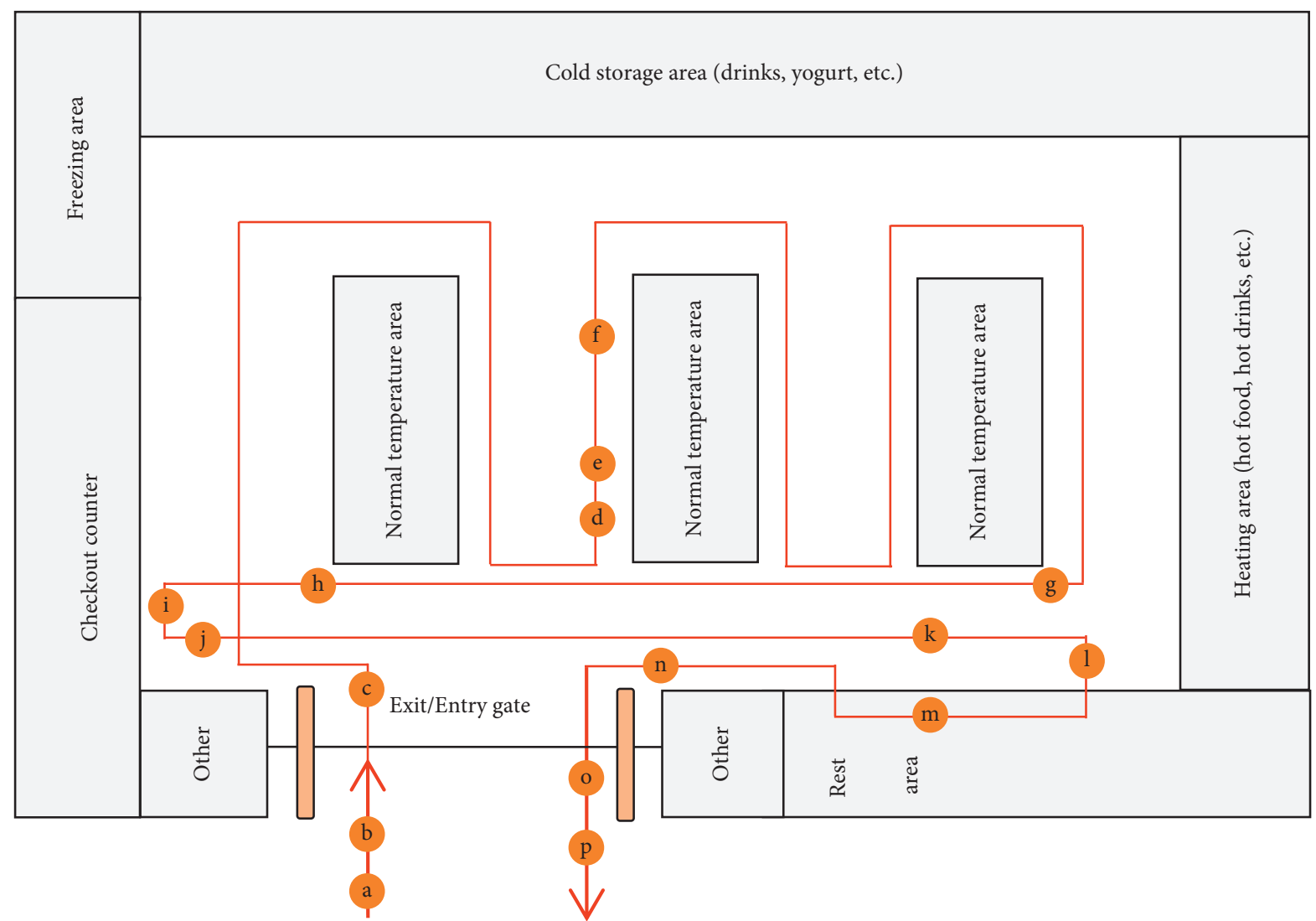

FIGURE 4: Customer journey map.

$$
\begin{aligned}
& \text { P: convenience store } \\
& \text { M: information } \\
& \text { C: consumer }
\end{aligned}
$$

FIGURE 5: Model analysis of touchpoint of commodity competition analysis.

TABLE 3: Summary of service touchpoints of convenience store system.

\begin{tabular}{lc}
\hline Method & Specific analysis \\
\hline $\begin{array}{l}\text { System resource } \\
\text { analysis }\end{array}$ & $\begin{array}{l}\text { The price of commodity in convenience stores is mainly determined by factors such as store personnel costs, } \\
\text { rental costs, and commodity costs. The internal resources of the labor cost system at the touchpoint of commodity } \\
\text { competition analysis mainly include new technologies, such as big data in the system, EPC system network, } \\
\text { artificial intelligence, data resources, logistics resources, etc. System external resources mainly include brand } \\
\text { vendors, suppliers, data resources outside the system, and the environmental field resources. }\end{array}$ \\
$\begin{array}{l}\text { Design constraint } \\
\text { analysis }\end{array}$ & $\begin{array}{l}\text { First, the selected sublevel standard solution can solve the problem of labor cost; secondly, the selected sublevel } \\
\text { standard solution should not increase or increase the cost of the merchant as much as possible; finally, the selected } \\
\text { sublevel standard solution is technically feasible. }\end{array}$ \\
\hline
\end{tabular}

of labor between humans and machines is carried out to reduce personnel input. Allocate human resources to assist and supervise the application of new technologies, and let the machine (technology) take on mechanized and repetitive tasks, such as cashiers, customer service, and replenishment. 
Such a convenience store only needs a manager, a number of self-service equipment (to perform tasks such as loading commodity, cashiers, etc.), and a background monitoring system platform, which realizes the reconstruction of the convenience store's people-goods-field. It not only reduces labor costs but also improves customer experience. The reconstructed service touchpoint model is shown in Figure 6.

Step 2. Query the type 3 standard solution to further improve the commodity competition analysis touchpoint system. The purpose is to optimize the system obtained by applying the type 1.2 standard solution to make the system composition more reasonable. In step 1, the standard solution (No. 9) was used to construct an effective and complete touchpoint model, allowing the new technology to take on manual work and thereby solve the problem of high labor costs in convenience stores. According to the guidance of type 3 standard solution, further improvements are made to the system. According to the analysis of system resources and design constraints in Table 3, standard solution No. 37 (to produce dual systems or multiple systems) is selected to continue optimizing the existing systems and transferring them to dual systems or multiple systems. In this way, a store manager, a number of self-service equipment, and a background monitoring system platform can be responsible for operating several convenience stores at the same time, so that the system can further reduce labor costs.

Step 3. After redesigning the questionnaire to analyze the optimized service touchpoints, it is found that the above concept is acceptable. At present, convenience stores have reduced labor costs by introducing new equipment, but they also need to improve the shopping experience of customers. Therefore, it is necessary to apply type 5 standard solution for further improvement.

Step 4 . The type 5 standard solution is to simplify or improve the solution obtained from the standard solution operations of type 1 to type 3 (introduction of substances/utilization of existing fields in the system/ state transfer/application of natural phenomena) to simplify the final problem solution. Through analysis, select No. 65 (using the existing field in the environment) in the type 5 standard solution to provide users with a leisure experience and enhance customers' shopping experience. On the basis of the existing food and beverage area, it provides convenient services such as self-service charging, self-service umbrella, selfservice express delivery, downloading and printing, dating and entertainment, etc., to increase user satisfaction with shopping by increasing excitement demand.

Through the above analysis, the convenience store service system has been optimized in two aspects, and the user experience has been initially improved: the first is to change to the store manager system unmanned

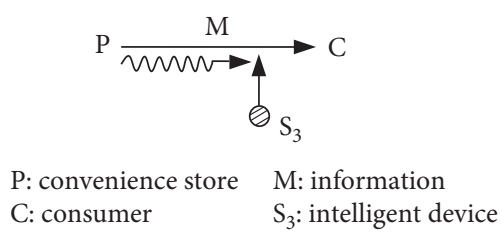

Figure 6: Optimized model of touchpoint of commodity competition analysis.

convenience store retail model. The payment method is changed to face ID payment, and then the cash register and cashier will be cancelled. This reduces the cost of convenience stores, while providing customers with more favorable and lower-profit commodity. It eliminates the bad experience of customers due to the high price of the commodity during the analysis of commodity competition, and also reduces the waiting time for queuing to pay. The second is to increase convenience services in the leisure area to provide customers with additional quality service experience. The touchpoints of the optimized convenience store service system are shown in Table 4:

\subsection{Construction of Service Touchpoint DSM in a Convenience Store System}

5.2.1. Draw a Directed Graph of the Convenience Store System. First, a directed graph of the convenience store system was drawn according to the relevant service touchpoints in the system optimized in 5.1 and their interactions, as presented in Figure 7.

5.2.2. Build the Initial DSM of Service Touchpoints of the Convenience Store System. There is a one-to-one correspondence between the directed graph and the DSM. According to the directed graph presented in Figure 7, the initial DSM of the convenience store system was determined, as exhibited in Table 5.

\subsection{Identification of Uncoupled and Coupled Service Touchpoints in the Convenience Store System}

5.3.1. Identification of Uncoupled-Associated Touchpoints of the Convenience Store System. The uncoupled-associated touchpoints of the initial DSM were identified and are presented in Table 5, where touchpoint A belongs to the zero row sum but no touchpoint belongs to the zero column sum. Therefore, only the touchpoint $\mathrm{A}$ in the convenience store system is an uncoupled-associated touchpoint.

\subsubsection{Identification of Coupled-Associated Touchpoints of the Convenience Store System}

(a) The touchpoint $A$ was eliminated from the initial DSM to obtain the incidence matrix $A$ of the initial DSM. 
TABLE 4: Summary of service touchpoints of the convenience store system.

\section{Shopping phase}

Before shopping

Shopping

After shopping
Service touchpoints

(a) Generate shopping demand

(b) Map navigation to the store

(c) New user registration

(d) Swipe your face to enter the store

(e) Browse store layout

(f) Find the commodity you need

(g) View commodity information

(h) Commodity competition analysis

(i) Identify the commodity (end of shopping)

(j) Swipe the face at the exit gate

(k) Check shopping list

(l) Confirm payment

(m) The gate opens and exits the gate

(n) Receive shopping list SMS

(o) Come to the leisure area

(p) Find a seat

(q) Entertainment/friendship/convenience services

(r) Evaluation feedback

(s) Leave the store

(t) After-sales service

$\begin{array}{ccccccccccccccccccc}0 & 0 & 0 & 0 & 0 & 0 & 0 & 0 & 0 & 0 & 0 & 0 & 0 & 0 & 0 & 0 & 0 & 0 & 0 \\ 1 & 0 & 0 & 0 & 0 & 0 & 0 & 0 & 0 & 0 & 0 & 0 & 0 & 1 & 0 & 0 & 0 & 0 & 0 \\ 1 & 1 & 0 & 0 & 0 & 0 & 0 & 0 & 0 & 0 & 0 & 0 & 1 & 0 & 0 & 0 & 0 & 0 & 0 \\ 0 & 0 & 1 & 0 & 0 & 0 & 0 & 0 & 0 & 0 & 0 & 0 & 0 & 0 & 0 & 0 & 0 & 0 & 0 \\ 0 & 0 & 1 & 1 & 0 & 1 & 1 & 1 & 0 & 1 & 0 & 0 & 0 & 0 & 0 & 0 & 0 & 0 & 0 \\ 0 & 0 & 0 & 0 & 1 & 0 & 0 & 0 & 0 & 0 & 0 & 0 & 0 & 0 & 0 & 0 & 0 & 0 & 0 \\ 0 & 0 & 0 & 0 & 0 & 1 & 0 & 0 & 0 & 0 & 0 & 0 & 0 & 0 & 0 & 0 & 0 & 0 & 0 \\ 0 & 0 & 0 & 0 & 0 & 1 & 1 & 0 & 0 & 0 & 0 & 0 & 0 & 0 & 0 & 0 & 0 & 0 & 0 \\ 0 & 0 & 0 & 0 & 0 & 0 & 0 & 1 & 0 & 0 & 0 & 0 & 0 & 0 & 0 & 0 & 0 & 0 & 0 \\ 0 & 0 & 0 & 0 & 0 & 0 & 0 & 0 & 1 & 0 & 0 & 0 & 0 & 0 & 0 & 0 & 0 & 0 & 0 \\ 0 & 0 & 0 & 0 & 0 & 0 & 0 & 0 & 0 & 1 & 0 & 0 & 0 & 0 & 0 & 0 & 0 & 0 & 0 \\ 0 & 0 & 0 & 0 & 0 & 0 & 0 & 0 & 1 & 0 & 1 & 0 & 0 & 0 & 0 & 0 & 0 & 0 & 0 \\ 0 & 0 & 0 & 0 & 0 & 0 & 0 & 0 & 0 & 0 & 0 & 1 & 0 & 0 & 0 & 0 & 0 & 0 & 0 \\ 1 & 1 & 0 & 0 & 0 & 0 & 0 & 0 & 0 & 0 & 0 & 0 & 1 & 0 & 0 & 0 & 0 & 0 & 0 \\ 0 & 0 & 0 & 0 & 0 & 0 & 0 & 0 & 0 & 0 & 0 & 0 & 0 & 1 & 0 & 0 & 0 & 0 & 0 \\ 0 & 0 & 0 & 0 & 0 & 0 & 0 & 0 & 0 & 0 & 0 & 0 & 0 & 0 & 1 & 0 & 0 & 0 & 0 \\ 0 & 0 & 0 & 0 & 0 & 0 & 0 & 0 & 0 & 0 & 0 & 0 & 0 & 0 & 0 & 1 & 0 & 1 & 1 \\ 0 & 0 & 0 & 0 & 0 & 0 & 0 & 0 & 0 & 0 & 0 & 0 & 0 & 0 & 0 & 0 & 1 & 0 & 0 \\ 0 & 0 & 0 & 0 & 0 & 0 & 0 & 0 & 0 & 0 & 0 & 0 & 0 & 0 & 0 & 0 & 0 & 1 & 0\end{array}$.




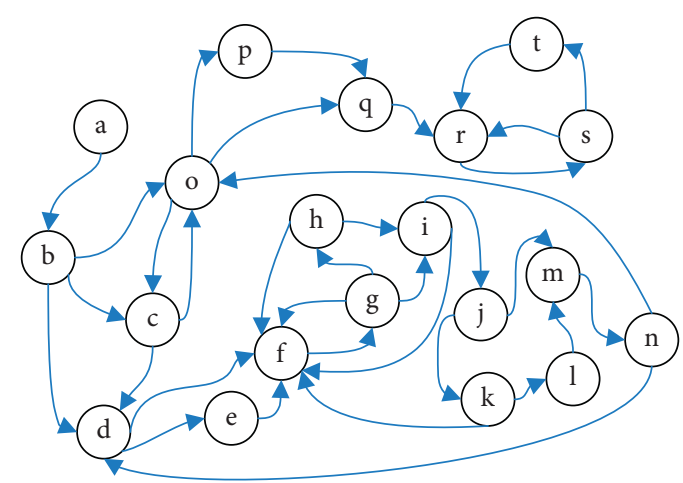

FIgURE 7: Directed diagram of service touchpoints in the convenience store system.

(b) The reachable matrix $P$ of the incidence matrix $A$ was determined.

$$
\begin{array}{ccccccccccccccccccc}
1 & 0 & 0 & 0 & 0 & 0 & 0 & 0 & 0 & 0 & 0 & 0 & 0 & 0 & 0 & 0 & 0 & 0 & 0 \\
1 & 1 & 1 & 1 & 1 & 1 & 1 & 1 & 1 & 1 & 1 & 1 & 1 & 1 & 0 & 0 & 0 & 0 & 0 \\
1 & 1 & 1 & 1 & 1 & 1 & 1 & 1 & 1 & 1 & 1 & 1 & 1 & 1 & 0 & 0 & 0 & 0 & 0 \\
1 & 1 & 1 & 1 & 1 & 1 & 1 & 1 & 1 & 1 & 1 & 1 & 1 & 1 & 0 & 0 & 0 & 0 & 0 \\
1 & 1 & 1 & 1 & 1 & 1 & 1 & 1 & 1 & 1 & 1 & 1 & 1 & 1 & 0 & 0 & 0 & 0 & 0 \\
1 & 1 & 1 & 1 & 1 & 1 & 1 & 1 & 1 & 1 & 1 & 1 & 1 & 1 & 0 & 0 & 0 & 0 & 0 \\
1 & 1 & 1 & 1 & 1 & 1 & 1 & 1 & 1 & 1 & 1 & 1 & 1 & 1 & 0 & 0 & 0 & 0 & 0 \\
1 & 1 & 1 & 1 & 1 & 1 & 1 & 1 & 1 & 1 & 1 & 1 & 1 & 1 & 0 & 0 & 0 & 0 & 0 \\
1 & 1 & 1 & 1 & 1 & 1 & 1 & 1 & 1 & 1 & 1 & 1 & 1 & 1 & 0 & 0 & 0 & 0 & 0 \\
P=1 & 1 & 1 & 1 & 1 & 1 & 1 & 1 & 1 & 1 & 1 & 1 & 1 & 1 & 0 & 0 & 0 & 0 & 0 \\
1 & 1 & 1 & 1 & 1 & 1 & 1 & 1 & 1 & 1 & 1 & 1 & 1 & 1 & 0 & 0 & 0 & 0 & 0 \\
1 & 1 & 1 & 1 & 1 & 1 & 1 & 1 & 1 & 1 & 1 & 1 & 1 & 1 & 0 & 0 & 0 & 0 & 0 \\
1 & 1 & 1 & 1 & 1 & 1 & 1 & 1 & 1 & 1 & 1 & 1 & 1 & 1 & 0 & 0 & 0 & 0 & 0 \\
1 & 1 & 1 & 1 & 1 & 1 & 1 & 1 & 1 & 1 & 1 & 1 & 1 & 1 & 0 & 0 & 0 & 0 & 0 \\
1 & 1 & 1 & 1 & 1 & 1 & 1 & 1 & 1 & 1 & 1 & 1 & 1 & 1 & 1 & 0 & 0 & 0 & 0 \\
1 & 1 & 1 & 1 & 1 & 1 & 1 & 1 & 1 & 1 & 1 & 1 & 1 & 1 & 1 & 1 & 0 & 0 & 0 \\
1 & 1 & 1 & 1 & 1 & 1 & 1 & 1 & 1 & 1 & 1 & 1 & 1 & 1 & 1 & 1 & 1 & 1 & 1 \\
1 & 1 & 1 & 1 & 1 & 1 & 1 & 1 & 1 & 1 & 1 & 1 & 1 & 1 & 1 & 1 & 1 & 1 & 1 \\
1 & 1 & 1 & 1 & 1 & 1 & 1 & 1 & 1 & 1 & 1 & 1 & 1 & 1 & 1 & 1 & 1 & 1 & 1
\end{array}
$$


TABLE 5: Initial DSM of the convenience store system.

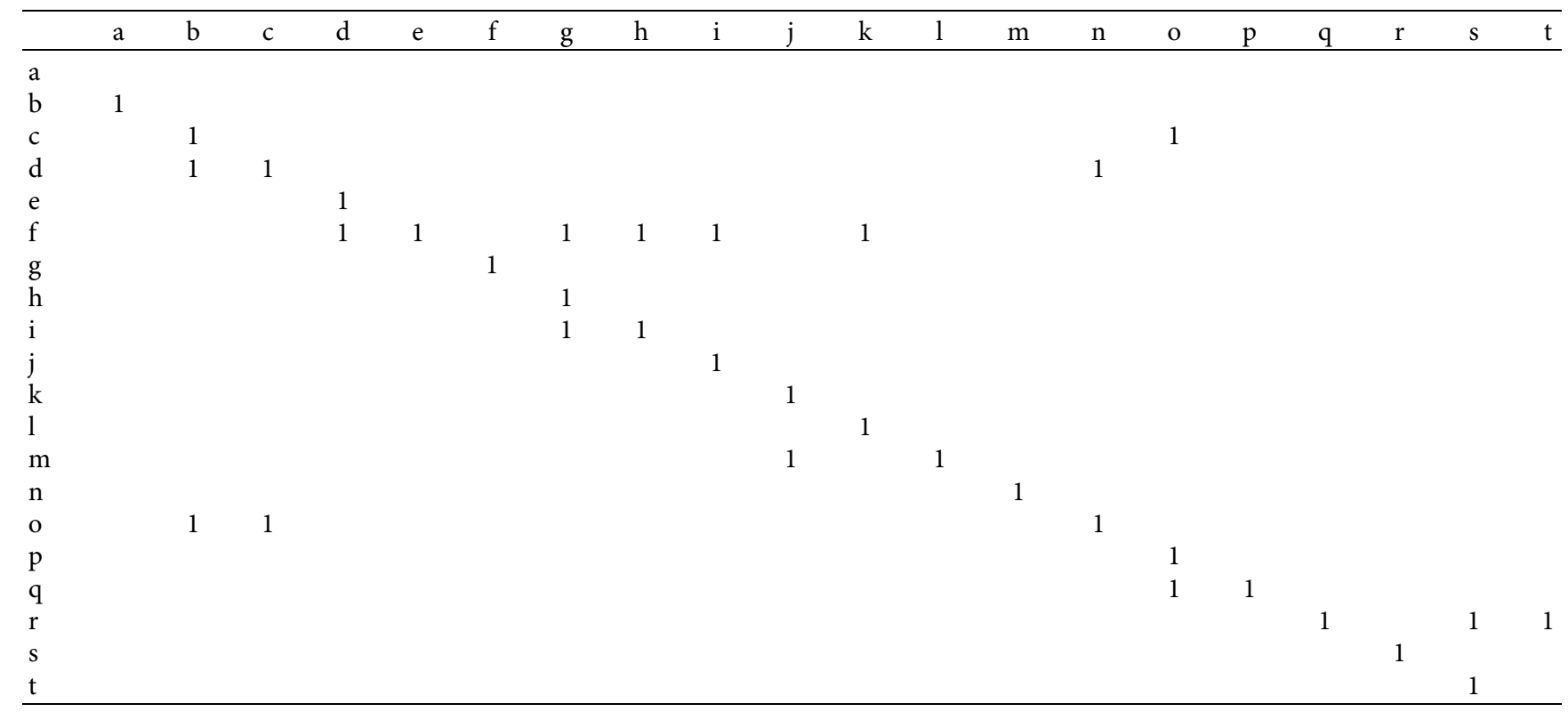

(c) The strongly connected matrix $Q$ and the strongly connected component of the incidence matrix $A$ were determined.

$$
\begin{array}{ccccccccccccccccccc}
1 & 0 & 0 & 0 & 0 & 0 & 0 & 0 & 0 & 0 & 0 & 0 & 0 & 0 & 0 & 0 & 0 & 0 & 0 \\
0 & 1 & 1 & 1 & 1 & 1 & 1 & 1 & 1 & 1 & 1 & 1 & 1 & 1 & 0 & 0 & 0 & 0 & 0 \\
0 & 1 & 1 & 1 & 1 & 1 & 1 & 1 & 1 & 1 & 1 & 1 & 1 & 1 & 0 & 0 & 0 & 0 & 0 \\
0 & 1 & 1 & 1 & 1 & 1 & 1 & 1 & 1 & 1 & 1 & 1 & 1 & 1 & 0 & 0 & 0 & 0 & 0 \\
0 & 1 & 1 & 1 & 1 & 1 & 1 & 1 & 1 & 1 & 1 & 1 & 1 & 1 & 0 & 0 & 0 & 0 & 0 \\
0 & 1 & 1 & 1 & 1 & 1 & 1 & 1 & 1 & 1 & 1 & 1 & 1 & 1 & 0 & 0 & 0 & 0 & 0 \\
0 & 1 & 1 & 1 & 1 & 1 & 1 & 1 & 1 & 1 & 1 & 1 & 1 & 1 & 0 & 0 & 0 & 0 & 0 \\
0 & 1 & 1 & 1 & 1 & 1 & 1 & 1 & 1 & 1 & 1 & 1 & 1 & 1 & 0 & 0 & 0 & 0 & 0 \\
0 & 1 & 1 & 1 & 1 & 1 & 1 & 1 & 1 & 1 & 1 & 1 & 1 & 1 & 0 & 0 & 0 & 0 & 0 \\
0 & 1 & 1 & 1 & 1 & 1 & 1 & 1 & 1 & 1 & 1 & 1 & 1 & 1 & 0 & 0 & 0 & 0 & 0 \\
0 & 1 & 1 & 1 & 1 & 1 & 1 & 1 & 1 & 1 & 1 & 1 & 1 & 1 & 0 & 0 & 0 & 0 & 0 \\
0 & 1 & 1 & 1 & 1 & 1 & 1 & 1 & 1 & 1 & 1 & 1 & 1 & 1 & 0 & 0 & 0 & 0 & 0 \\
0 & 1 & 1 & 1 & 1 & 1 & 1 & 1 & 1 & 1 & 1 & 1 & 1 & 1 & 0 & 0 & 0 & 0 & 0 \\
0 & 1 & 1 & 1 & 1 & 1 & 1 & 1 & 1 & 1 & 1 & 1 & 1 & 1 & 0 & 0 & 0 & 0 & 0 \\
0 & 0 & 0 & 0 & 0 & 0 & 0 & 0 & 0 & 0 & 0 & 0 & 0 & 0 & 1 & 0 & 0 & 0 & 0 \\
0 & 0 & 0 & 0 & 0 & 0 & 0 & 0 & 0 & 0 & 0 & 0 & 0 & 0 & 0 & 1 & 0 & 0 & 0 \\
0 & 0 & 0 & 0 & 0 & 0 & 0 & 0 & 0 & 0 & 0 & 0 & 0 & 0 & 0 & 0 & 1 & 1 & 1 \\
0 & 0 & 0 & 0 & 0 & 0 & 0 & 0 & 0 & 0 & 0 & 0 & 0 & 0 & 0 & 0 & 1 & 1 & 1 \\
0 & 0 & 0 & 0 & 0 & 0 & 0 & 0 & 0 & 0 & 0 & 0 & 0 & 0 & 0 & 0 & 1 & 1 & 1
\end{array}
$$


According to the strongly connected matrix, there are five strongly connected components in the incidence matrix $A:\{b\},\{c, d, e, f, g, h, i, j, k, l, m, n, o\},\{p\},\{q\}$, and $\{r, s, t\}$. After excluding the coupled touchpoints, the convenience store service process was divided into five modules.

\subsection{Level Analysis of Convenience Store Service Touchpoints.}

(1)

Level analysis of uncoupled-associated convenience store service touchpoints. Touchpoint $A$ belongs to the zero line sum, so arranging the touchpoint at the front of the line takes precedence.

(2) Level analysis of coupled-associated convenience store service touchpoints.

$$
p 1=\begin{array}{lllll}
1 & 0 & 0 & 0 & 0 \\
1 & 1 & 0 & 0 & 0 \\
1 & 1 & 1 & 0 & 0 \\
1 & 1 & 1 & 1 & 0 \\
1 & 1 & 1 & 1 & 1
\end{array}
$$

(a) Touchpoint $c$ was selected to represent the strongly connected components $\{c, d, e, f, g, h, i, j, k, l, m, n$, $o\}$. Touchpoint $r$ was selected to represent the strongly connected components $\{r, s, t\}$. The corresponding rows and columns of $\{j, k, l, m, n, o\}$ with $\{s, t\}$ in the convenience store reachable matrix were deleted, and a $5 \times 5$ reduced matrix $P^{\prime}$ was obtained.

(b) The reachable set $R(V i)$ and the predecessor set $A$ ( $V i)$ of the incidence matrix $A$ were determined according to the reduction matrix $P^{\prime}$, and the intersection $R(V i) \cap A(V i)$ was determined from the predecessor set and the reachable set, as shown in Table 6. The element of $R(V i) \cap A(V i)=R(V i)$ was found to be $b$, and $b$ is then the highest layer L1 in the strongly connected subset.

(c) The highest level of the coupling set was removed, and step $(b)$ was repeated. In turn, the level relationship of the coupling set was determined.

(3) According to the order of coupled- and uncoupledassociated touchpoints, the overall level relationship of each touchpoint module was obtained. As shown in Table 7, the convenience store service process was divided into 6 levels in total.

By combining the touchpoint level relationship table and the service system directed graph established in Section 5.2, a modularized and layered directed graph of the convenience store system was obtained, as presented in Figure 8.

\section{Results and Discussion}

By comparing the directed graph after optimization with that before optimization, it is evident that the directed graph before optimization is chaotic and unorganized; the number of modules is 0 ; and it is not clear which touchpoints have strong associations. It is possible to arrange the strongly associated touchpoints in different positions or with no association, and the process is unclear. It needs to go back and find to complete the entire process, which would affect the service experience.

The directed graph after clustering identification and level division is divided into 6 simpler modules for information transmission. The service touchpoints in each module maintain strong association relationships, while each module maintains a weak association relationship. The level relationship is clear at a glance, and the order of execution is clearly visible. The optimized directed graph provides effective guidance for the logical design of the orientation, layout, location, and distance between each service touchpoint, thereby improving the service experience. Even if the existing conditions cannot be changed, some eye-catching related information can be added at specific locations according to the flowchart to visually associate the touchpoints, thereby improving the service experience.

According to the optimized directed graph, the main flow chart of the convenience store service system was redesigned, including the layout of the touchpoints. The execution order of the touchpoints should correspond to the level in Figure 8. For example, touchpoint $p$ (find seat) belongs to level 4 , and touchpoint $q$ (entertainment/ friends/convenience service) belongs to level 5, so $p$ must be executed before $q$; The touchpoints in any level should not be set too far away, it is better to set a guide flag. For example, touchpoint $l$ (determine payment) and $o$ (come to leisure area)) belong to the same level, so the location should be as close as possible when designing the process. Before optimization, the two touchpoints were too far apart, causing customers to experience repeated routes; change the arrangement of shelves from side-by-side to surrounding. The aim is to prevent customers having to repeat the route multiple times between touchpoint $e$ (browse the store layout) and touchpoint $i$ (end of shopping). The customer shopping process mainly includes the following stages. As presented in Figure 9. (1) The face-/ code-scanning entry stage: the customer enters the store by scanning his or her face or scanning a code from an app (first-time entry requires registration). The entry gate can communicate customer information to the store manager cloud server. (2) The product selection stage: when a customer picks up goods from a shelf, the intelligent shelf can automatically record the customer's shopping list based on the customer's information in the cloud, and can monitor the quantity and type of commodity. (3) The face-/ code-scanning payment stage: when the customer arrives at the exit gate that is connected to the cloud service to scan his or her face or code, the gate screen displays the customer's shopping information. The exit gate then opens and the customer walks out of the store to complete his or her shopping. Within 15 minutes, customers can receive an electronic shopping list. (4) The entertainment stage: customers can choose to dine in the entertainment area, download and print documents, rent and lend media, collect packages, and other activities. 
TABLE 6: Reachable set, predecessor set, and their intersection.

\begin{tabular}{lccc}
\hline Node & Reachable set $R(V i)$ & Predecessor set $\underline{A}(V i)$ & $R(V i) \cap A(V i)$ \\
\hline $\mathrm{b}$ & $\mathrm{b}$ & $\mathrm{b}, \sum \mathrm{c}, \mathrm{p}, \mathrm{q}, \sum \mathrm{r}$ & $\mathrm{b}$ \\
$\sum \mathrm{c}$ & $\mathrm{b}, \sum \mathrm{c}$ & $\sum \mathrm{c}, \mathrm{p}, \mathrm{q}, \sum \mathrm{r}$ & $\sum \mathrm{c}$ \\
$\mathrm{p}$ & $\mathrm{b}, \sum \mathrm{c}, \mathrm{p}$ & $\mathrm{p}, \mathrm{q}, \sum \mathrm{r}$ & $\mathrm{p}$ \\
$\mathrm{q}$ & $\mathrm{b}, \sum \mathrm{c}, \mathrm{p}, \mathrm{q}$ & $\mathrm{q}, \sum \mathrm{r}$ & $\mathrm{q}$ \\
$\sum \mathrm{r}$ & $\mathrm{b}, \sum \mathrm{c}, \mathrm{p}, \mathrm{q}, \sum \mathrm{r}$ & $\sum \mathrm{r}$ & $\sum \mathrm{r}$ \\
\hline
\end{tabular}

TABLE 7: Overall level relationship table of the convenience store touchpoints.

\begin{tabular}{lr}
\hline Level & Touchpoints \\
\hline L1 & a \\
L2 & b, c, d, e, f, g, h, i, j, k, l, m, n, o \\
L3 & p \\
L4 & q \\
L5 & r, s, t \\
L6 & \\
\hline
\end{tabular}

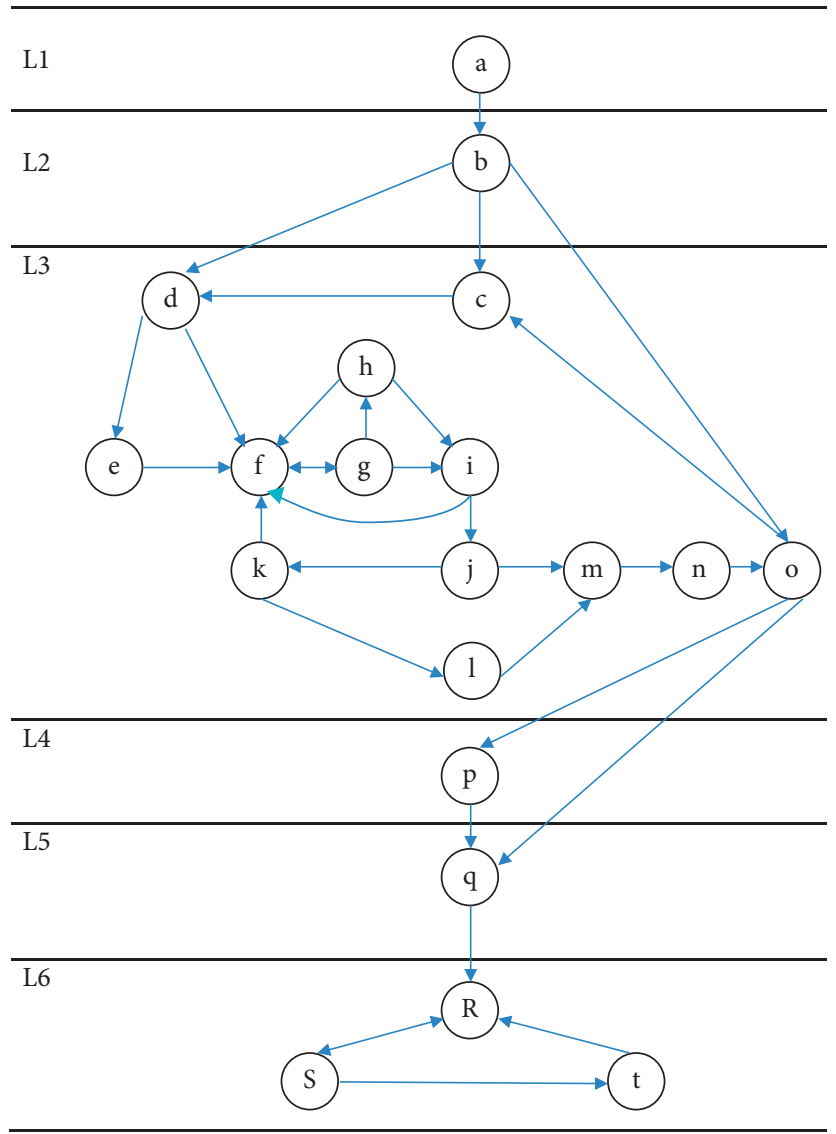

FIGURE 8: The directed graph of the optimized convenience store system.

Compared with the customer journey map before optimization, the optimized flowchart does not have repeated tortuous routes, and it relies on new technologies such as big data, cloud platforms, and EPC system network to provide users with a brand new and smoother offline retail shopping experience. In a convenience store, users can not only obtain high-quality and low-cost commodity efficiently but also enjoy convenient services such as downloading and printing, renting and lending, and picking up and collecting express delivery. At the same time, it also empowers users to successfully complete their shopping without the interruption of staff, which enhances the user's sense of pleasure in the shopping process and the sense of accomplishment of successful shopping. 


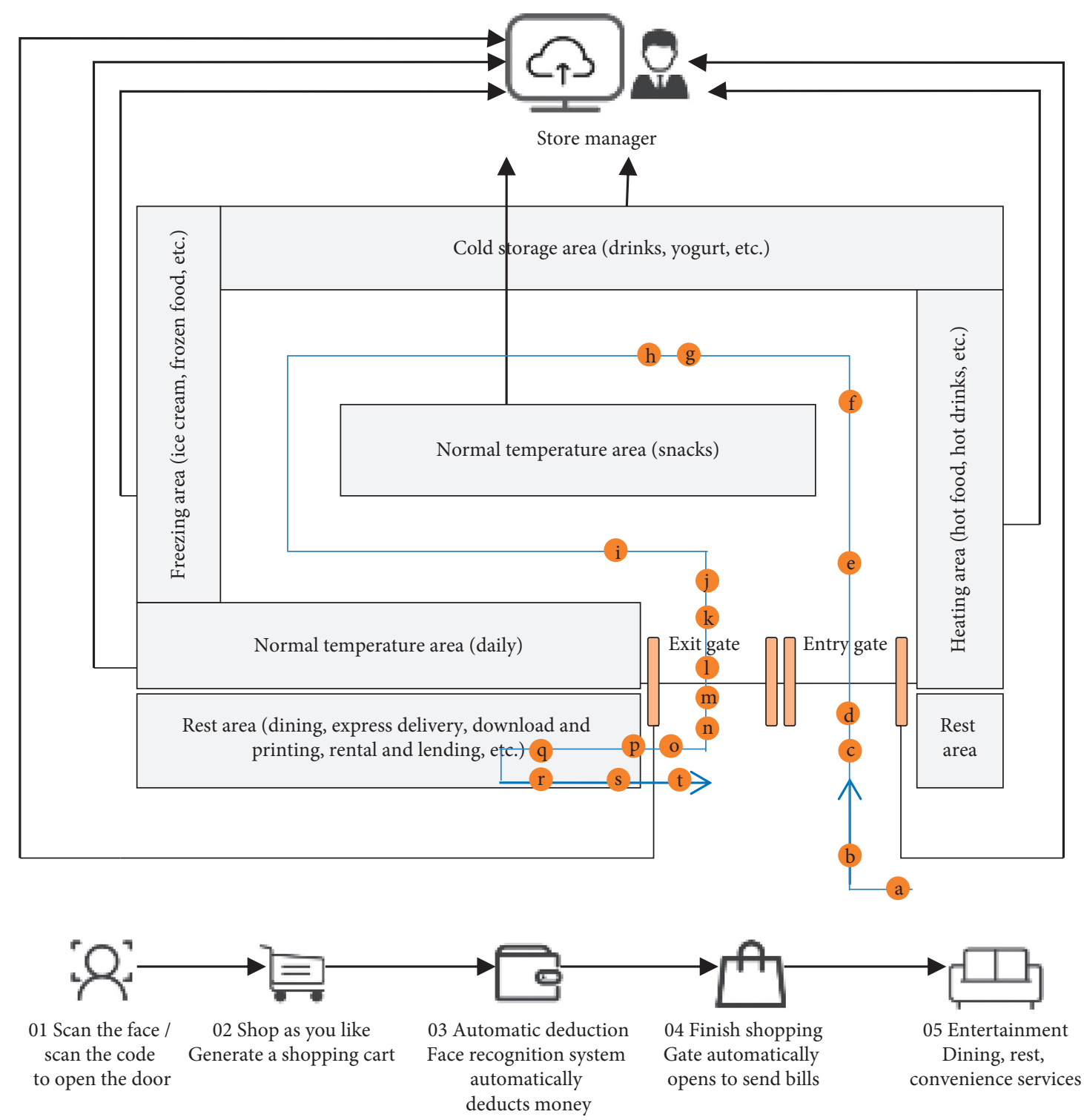

FIgURE 9: The main flowchart of the convenience store service system.

Carrying out modularization and layering on the service process and decomposing the complex service process into modules composed of different service touchpoints has the following beneficial effects on the operation of convenience stores: (1) The optimization of the service process enables customers to enjoy a better experience, enhances the reputation of merchants, and correspondingly brings better benefits to convenience stores. (2) Able to achieve modular management of services to give full play to the expertise of each department, and effectively control the generation and removal of service problems. For example, level 3 is managed by the business department, while level 6 is managed by the after-sales department. (3) It is conducive to the derivation of service organizations and the realization of outsourcing agents to obtain economies of scale. Service outsourcing can be implemented by the map navigation included in Level 2 and convenient services included in Level 5. The purpose is to use the advantages of external resources to obtain more benefits.

\section{Conclusion}

This paper expands the application scope of the DSM to the optimization of service design from the perspective of the association of service touchpoints. This paper systematically introduces a service process optimization flow based on the DSM on the premise of single touchpoint optimization, including the construction of a service touchpoint DSM, the identification of service touchpoints, and the level analysis of service touchpoints. Case studies have demonstrated that a DSM can achieve the optimization of complex service processes by fully taking into account the association of touchpoints. It avoids the one-sidedness caused by the traditional optimization method, which only considers a single touchpoint and cannot reasonably organize the logical association between the touchpoints.

The goal of this work was to improve the service experience and provide a reference for complex service process 
optimization; however, there remained certain limitations to this study. In the model proposed in this paper, the touchpoints with high association are modularized and layered; however, the order of the touchpoints within the module after modularization is not considered. In addition, customer needs should be taken into account when optimizing service processes. Therefore, the proposed method of complex service process optimization from the perspective of service touchpoints requires further study.

\section{Data Availability}

The relevant data in this article were obtained by the author's personal investigation and research and can be made available upon request.

\section{Conflicts of Interest}

The authors declare that there are no conflicts of interest regarding the publication of this paper.

\section{References}

[1] R. Thakur and D. Hale, "Service innovation: a comparative study of U.S. and Indian service firms," Journal of Business Research, vol. 66, no. 8, pp. 1108-1123, 2013.

[2] J. Vink, B. Edvardsson, K. Wetter-Edman, and B. Tronvoll, "Reshaping mental models-enabling innovation through service design," Journal of Service Management, vol. 30, no. 1, pp. 75-104, 2019.

[3] K. Wetter-Edman, J. Vink, and J. Blomkvist, "Staging aesthetic disruption through design methods for service innovation," Design Studies, vol. 55, pp. 5-26, 2018.

[4] A. L. Ostrom, M. J. Bitner, S. W. Brown et al., "Moving forward and making a difference: research priorities for the science of service," Journal of Service Research, vol. 13, no. 1, pp. 4-36, 2010.

[5] M. P. Joly, J. G. Teixeira, L. Patrício, and D. Sangiorgi, "Leveraging service design as a multidisciplinary approach to service innovation," Journal of Service Management, vol. 30, pp. 681-715, 2019.

[6] Y.-H. Wang, C.-H. Lee, and A. J. C. Trappey, "Service design blueprint approach incorporating TRIZ and service QFD for a meal ordering system: a case study," Computers \& Industrial Engineering, vol. 107, pp. 388-400, 2017.

[7] Q. Luo, "User-oriented service design and innovation," in Proceedings of the 2011 International Conference of Information Technology, Computer Engineering and Management Sciences, Nanjing, China, 2011.

[8] C. Deng, "Touch the service touchpoints," Zhuangshi, vol. 6, pp. 13-17, 2010.

[9] X. Xiangyang, "Interaction design: from logic of things to logic of behaviors," Zhuangshi, vol. 1, pp. 58-62, 2015.

[10] C.-H. Lee, X. Zhao, and Y.-C. Lee, "Service quality driven approach for innovative retail service system design and evaluation: a case study," Computers \& Industrial Engineering, vol. 135, pp. 275-285, 2019.

[11] E. Pantano and M. Viassone, "Engaging consumers on new integrated multichannel retail settings: challenges for retailers," Journal of Retailing and Consumer Services, vol. 25, pp. 106-114, 2015.
[12] C. Meyer and A. Schwager, "Understanding customer experience," Harvard Business Review, vol. 85, no. 2, pp. 116157, 2007.

[13] R. Halvorsrud, K. Kvale, and A. Følstad, "Improving service quality through customer journey analysis," Journal of Service Theory and Practice, vol. 26, pp. 840-867, 2007.

[14] S. Baxendale, E. K. Macdonald, and H. N. Wilson, "The impact of different touchpoints on brand consideration," Journal of Retailing, vol. 91, no. 2, pp. 235-253, 2015.

[15] M. S. Rosenbaum, M. L. Otalora, and G. C. Ramírez, "How to create a realistic customer journey map," Business Horizons, vol. 60, no. 1, pp. 143-150, 2017.

[16] C.-H. Lee, C.-H. Chen, F. Li, and A.-J. Shie, "Customized and knowledge-centric service design model integrating casebased reasoning and TRIZ," Expert Systems with Applications, vol. 143, Article ID 113062, 2020.

[17] C.-H. Lee, Y.-H. Wang, and A. J. C. Trappey, "Service design for intelligent parking based on theory of inventive problem solving and service blueprint," Advanced Engineering Informatics, vol. 29, no. 3, pp. 295-306, 2015.

[18] Y.-H. Wang, C.-H. Lee, and A. J. C. Trappey, "Modularized design-oriented systematic inventive thinking approach supporting collaborative service innovations," Advanced Engineering Informatics, vol. 33, pp. 300-313, 2017.

[19] C.-H. Lee, C.-H. Chen, and Y.-C. Lee, "Customer requirement-driven design method and computer-aided design system for supporting service innovation conceptualization handling," Advanced Engineering Informatics, vol. 45, Article ID 101117, 2020.

[20] S. Clatworthy, "Service innovation through touch-points: development of an innovation toolkit for the first stages of new service development," International Journal of Design, vol. 5, pp. 15-28, 2011.

[21] D. V. Steward, "The design structure system: a method for managing the design of complex systems," IEEE Transactions on Engineering Management, vol. 28, no. 3, pp. 71-74, 1981.

[22] T. R. Browning, "Applying the design structure matrix to system decomposition and integration problems: a review and new directions," IEEE Transactions on Engineering Management, vol. 48, no. 3, pp. 292-306, 2001.

[23] P. Ben-hong and L. Qian, "Optimization to service modular: based on PCN," Technology Ecnonmics, vol. 34, pp. 14-20, 2015.

[24] Z. Bai, H. Sun, and J.-1. Zhang, "Service contact point optimization based on TRIZ and analog design," Packaging Engineering, vol. 41, no. 16, pp. 91-97, 2020.

[25] L. A. Mohr and M. J. Bitner, "The role of employee effort in satisfaction with service transactions," Journal of Business Research, vol. 32, no. 3, pp. 239-252, 1995.

[26] G. L. Shostack, Planning the Service Encounter, Lexington Books, Lexington, MA, USA, 1985.

[27] B. Larivière, D. Bowen, T. W. Andreassen et al., "“Service encounter 2.0": an investigation into the roles of technology, employees and customers," Journal of Business Research, vol. 79, pp. 238-246, 2017.

[28] M. R. Solomon, C. Surprenant, J. A. Czepiel, and E. G. Gutman, "A role theory perspective on dyadic interactions: the service encounter," Journal of Marketing, vol. 49, no. 1, p. 99, 1985.

[29] M. Zhu, X. Yan, and Q. Yuan, "Service encounter theory and its application and prospect in information system," Journal of Modern Informattion, vol. 39, pp. 149-159, 2019.

[30] Y. D. Volpi and S. R. Paulino, "The sustainability of services: considerations on the materiality of accommodation services 
from the concept of life cycle thinking," Journal of Cleaner Production, vol. 194, pp. 327-334, 2018.

[31] M. E. Pullman and M. A. Gross, "Ability of experience design elements to elicit emotions and loyalty behaviors," Decision Sciences, vol. 35, no. 3, pp. 551-578, 2004.

[32] W. Wang, T. Wei, Y. Zhang, and Y. Wang, "A method of intelligent product design cue construction based on customer touchpoint correlation analysis and positive creativity theory," Advances in Mechanical Engineering, vol. 11, pp. 1$11,2019$.

[33] S. Kim, J. J. E. Chang, H. H. Park et al., "Autonomous taxi service design and user experience," International Journal of Human-Computer Interaction, vol. 36, no. 5, pp. 429-448, 2019.

[34] C. H. Lee, C. H. Chen, C. Lin, F. Li, and X. Zhao, "Developing a quick response product configuration system under industry 4.0 based on customer requirement modelling and optimization method," Applied Sciences, vol. 9, no. 23, p. 5004, 2019.

[35] L. Patrício, R. P. Fisk, J. Falcão e Cunha, and L. Constantine, "Multilevel service design: from customer value constellation to service experience blueprinting," Journal of Service Research, vol. 14, no. 2, pp. 180-200, 2011.

[36] V. Roto, H. Väätäjä, E. Law, and R. Powers, "Experience design for multiple customer touchpoints," in Proceedings of the 9th Nordic Conference on Human-Computer Interaction (NordiCHI), New York, NY, USA, 2016.

[37] X. Li, "Research on the service design of pediatric medical institution," Zhuangshi, vol. 2, pp. 106-109, 2018.

[38] J. Cheng, Research on the construction of the touch point of meseum display from the perspective of service design, Ph.D. thesis, Central China Normal University, Wuhan, China, 2017.

[39] P. Carlborg and D. Kindström, "Service process modularization and modular strategies," Journal of Business \& Industrial Marketing, vol. 29, no. 4, pp. 313-323, 2014.

[40] J. Luo, Y. Zhang, and Y. Peng, "Research on service-oriented manufacturing system process improvements based on service blueprint," China Mechanical Engineering, vol. 29, pp. 2250-2258, 2018.

[41] A. Tripathy and S. D. Eppinger, "Structuring work distribution for global product development organizations," Production and Operations Management, vol. 22, no. 6, pp. 1557-1575, 2013.

[42] E. Danie and Whitney, "Designing the design process," Research in Engineering Design, vol. 2, pp. 3-13, 1990.

[43] M. S. Park, G. Y. Cho, H. S. Lee, and S. K. Kwon, "BIM design management process using the dependency structure matrix at the introduction phase," Journal of the Architectural Institute of Korea Planning \& Design, vol. 28, pp. 37-45, 2012.

[44] R. M. Sari, A. R. Matondang, and K. Syahputri, "Sequencing of dust filter production process using design structure matrix (DSM)," IOP Conference Series: Materials Science and Engineering, vol. 288, pp. 1-6, 2018.

[45] D. Marjanović, M. Štorga, S. Škec, N. Bojčetić, and N. Pavković, "Augmented DSM sequencing to support product development planning," in Proceedings of the 2018 International Design Conference, New Orleans, LA, USA, 2018.

[46] X. Zhang, S. Ma, and S. Chen, "Healthcare process modularization using design structure matrix," Advanced Engineering Informatics, vol. 39, pp. 320-330, 2019.

[47] L. Yang and M. Y. Shan, "Service module identification for mass customization," in Proceedings of the 2008 International
Conference of Production and Operation Management, Xiamen, China, 2008.

[48] J.-c. Cong, C.-H. Chen, P. Zheng, X. Li, and Z. Wang, "A holistic relook at engineering design methodologies for smart product-service systems development," Journal of Cleaner Production, vol. 272, Article ID 122737, 2020.

[49] Y. Fu and X. Gu, Discrete Mathematics and Its Applications, Electronic Industry Press, Beijing, China, 1997.

[50] Y. Lin, Research on approaches of business process modeling and reengineering based on design structure matrix (DSM), Ph.D. thesis, Northeastern University, Shenyang, China, 2011. 